
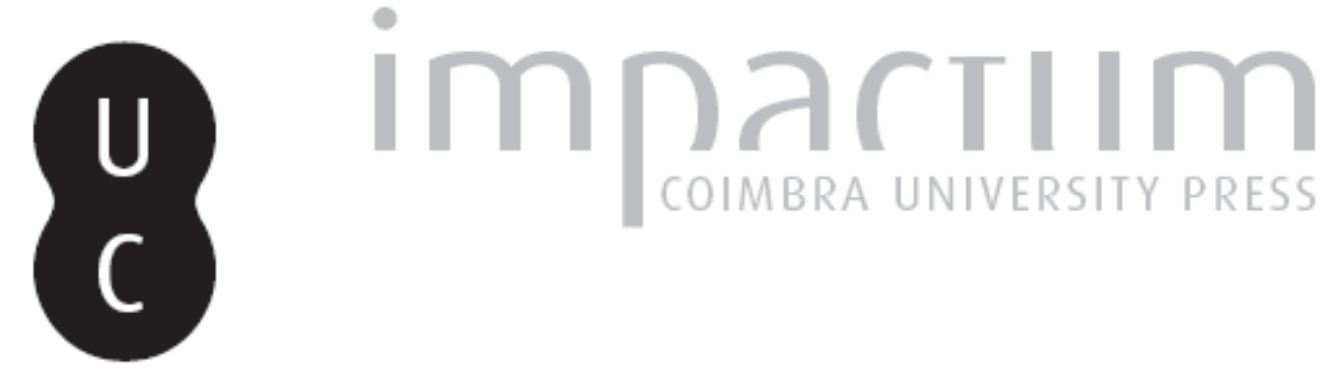

\title{
[Recensão a] Ojeda Torres, Juan Matías, El Servicio Administrativo Imperial Ecuestre en la Hispania Romana durante el Alto Imperio: I. Prosopografia
}
Autor(es):
D’Encarnação, José

Publicado por: Imprensa da Universidade de Coimbra

URL persistente:

URI:http://hdl.handle.net/10316.2/45472

DOI:

DOI:https://dx.doi.org/10.14195/1647-8657_34_14

Accessed : $\quad$ 26-Apr-2023 15:55:37

A navegação consulta e descarregamento dos títulos inseridos nas Bibliotecas Digitais UC Digitalis, UC Pombalina e UC Impactum, pressupõem a aceitação plena e sem reservas dos Termos e Condições de Uso destas Bibliotecas Digitais, disponíveis em https://digitalis.uc.pt/pt-pt/termos.

Conforme exposto nos referidos Termos e Condições de Uso, o descarregamento de títulos de acesso restrito requer uma licença válida de autorização devendo o utilizador aceder ao(s) documento(s) a partir de um endereço de IP da instituição detentora da supramencionada licença.

Ao utilizador é apenas permitido o descarregamento para uso pessoal, pelo que o emprego do(s) título(s) descarregado(s) para outro fim, designadamente comercial, carece de autorização do respetivo autor ou editor da obra.

Na medida em que todas as obras da UC Digitalis se encontram protegidas pelo Código do Direito de Autor e Direitos Conexos e demais legislação aplicável, toda a cópia, parcial ou total, deste documento, nos casos em que é legalmente admitida, deverá conter ou fazer-se acompanhar por este aviso.

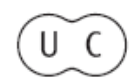


UNIVERSIDADE DE COIMBRA

FACULDADE DE LETRAS

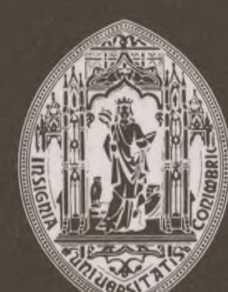

CONIMBRIGA

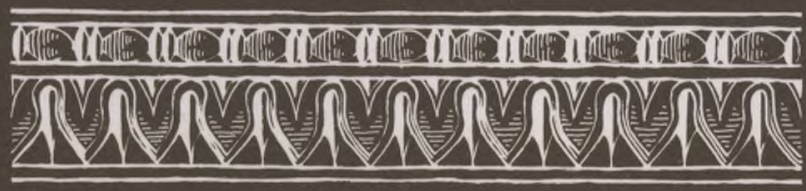

VOLUME XXXIV - 1995

INSTITUTO DE ARQUEOLOGIA 
Sendo, portanto, Pompeius um gentilicio e precedendo os cognomes, não se pode deixar de concordar com Alain Tranoy (cf. também José Manuel GARCIA, Religiões Antigas de Portugal, Lisboa, 1991, 366).

O paralelismo é evidente: em ambos os casos, um gentilicio comum, no plural, apesar de surgir em diferente posição. As regras epigráficas confirmam, portanto, a interpretação de Milagros Navarro: estamos perante libertos (e não escravos) que, devido ao modo de identificação escolhido, omitiram aqui o seu praenomen, decerto o mesmo, por ser o do seu patrono.

Não quereria, porém, terminar esta apreciaçao a uma obra primogénita cuja 'família' desejamos ver rapidamente acrescentada - sem me congratular com a referência, na p. 64, a João Baptista Labaña, um cartógrafo português ao serviço de Filipe II, que, no decurso duma viagem pelo reino de Aragão, foi anotando no seu itinerário tudo quanto lhe pareceu de interesse. Aos seus apontamentos se ficou a dever, assim, o conhecimento de duas inscrições de Albarracín e dos blocos de Calomarde. Mais uma vez, os manuscritos antigos ao serviço da Epigrafia.

JoSÉ D'ENCARNAÇÃO

OJEDA TORRES, Juan Matías, EI Servicio Administrativo Imperial Ecuestre en la Hispania Romana durante el Alto Imperio: I. Prosopografia. $\mathrm{N} .{ }^{\circ} 2$ da colecção «Publicaciones Ocasionales» de KOLAIOS (Asociación Cultural para el Estudio de la Antigüedad), Sevilha, 1993. 283 pp. ISBN: 84-605-0019-5.

Propõe-se o Autor contribuir para a determinação do que foram as linhas mestras da administração provincial durante o Império romano, desde Augusto a Galieno, na Península Ibérica. Uma tarefa que, como bem assinala, pressupõe, depois duma recolha exaustiva do material (sobretudo epigráfico) disponível, a sua análise pormenorizada. Daí que a primeira preocupação de Ojeda Torres se tenha centrado no cuidadoso levantamento de todos os dados prosopográficos referentes a cavaleiros cuja acção aqui se documentou.

Após ter clarificado os conceitos de «ordem equestre» e de «ordem senatorial», Ojeda Torres sublinha a importância que detinha para o escol municipal o ingresso na carreira equestre, através do exercício da profectura fabrum. Só, porém, nos finais do século I da nossa era se começou a escalonar melhor um cursus cujas fases nem sempre se lograram determinar com nitidez, designadamente no que respeitava ao vencimento auferido ou ao tempo de exercício fixado para cada função.

O catálogo estabelecido pelo Autor contém o currículo de 64 cavaleiros de cuja actividade administrativa na Península - 73 cargos, no total - se encontra eco nas fontes consultadas. Os quadros apresentados nas pp. 26 a 39, devidamente comentados e referentes aos séculos I, II e III, são logo deveras elucidativos, a permitir algumas conclusões: só a partir dos Flávios é que se torna possível tentar uma sistematização dos cargos de acordo com a remuneração auferida; sistematização que, de resto, nunca se poderá considerar única e definitiva, pois é legítimo supor que a rigidez nunca terá sido regra a cumprir.

Conimbriga, 34 (1995), p. $205-222$ 
Interessante será verificar, desde já, que, no século II, são quatro as funções documentadas:

- o procurador ad ripam Baetis, que Ojeda Torres considera dever entender-se «como uma função a largo prazo e não uma missão pontual sem continuidade, já que a navegabilidade do rio era primordial para a economia da Bética e, portanto, as obras para a construção dos diques e canais (...) não podiam estar em mãos de iniciativas particulares desconexas» (p. 30);

- o procurador encarregado de cobrar os 5\% de imposto sucessório na Bética e na Lusitânia, por um lado, na Hispânia Citerior, por outro;

- finalmente, o ajudante do prefeito da anona em tudo o que respeita ao azeite hispânico e africano, um cargo que poderá não ter sido extraordinário mas sim normal, porquanto havia que «apagar das despesas do transporte $\mathrm{e}$ as indemnizações devidas pela venda obrigatória ao Estado» (p. 30).

A partir de Septimio Severo, esses cargos mantêm-se e documenta-se também um outro (como sinal dos tempos!), o de procurador da familia gladiatoria em toda a Europa Ocidental, exercido, por exemplo, por L. Didius Marinus (o n. ${ }^{\circ}$ 59 do catálogo). Cessa, todavia, então, o do procurador do kalendarium Vegetianum na Bética, «função específica para a administração dos rendimentos dos bens da família dos Valerii Vegeti» (p. 23).

No que toca à origem dos cavaleiros mencionados, é nítido o predomínio de itálicos e, também, de hispânicos, estes de modo particular na Bética, como é natural, dadas as características ímpares da sua população: dos dezasseis casos com naturalidade conhecida aqui documentados, há dois do Oriente, três africanos, um de Roma e dez da Península (oito da Bética e dois de Cástulo) (p. 35). Uma prova, como muito bem conclui o Autor, de como a política romana soube aproveitar ao máximo as eficazes potencialidades que lhe eram oferecidas pela fina-flor «local plenamente integrada no modus vivendi romano» (p. 36).

Os dados obtidos hão-de ser cotejados, depois, com o que se sabe da política geral de Roma, porque a história dos grandes homens não pode desgarrar-se do seu contexto; são, em certa medida, produtos de um meio e não podem agir sem o apoio de clientelas. E esse um dos objectivos que se anuncia para o segundo volume da obra. No entanto, algumas pistas já o Autor enuncia agora. Ao verificar, por exemplo, que se documenta uma alta percentagem de funcionários imperiais equestres entre o reinado de Cómodo e o começo do principado de Caracala, ou seja, desde os finais da dinastia dos Antoninos até aos primeiros anos dos Severos, Ojeda Torres não hesita em conotá-la com «as profundas reformas de descentralização administrativa» levadas a cabo por Septimio Severo, que tanto apoiou os cavaleiros em detrimento da classe senatorial conservadora, assim como com «o aumento da pressão fiscal para solucionar os problemas de abastecimento e de salário dos soldados» que o mesmo imperador aumentou substancialmente para recompensar os seus apoiantes (p. 38).

Constitui o catálogo o cerne da obra em apreço. As carreiras estão ordenadas por província e cronologicamente. A cada cavaleiro - citado, sempre que possível, pelo nome completo - foi atribuído um número de referência, seguindo-se: a enumeração dos cargos ocupados; a datação; as fontes em que foi beber-se a informação; o reportório bibliográfico; o currículo ordenado de acordo com a sua 
natural progressão (incluindo os cargos municipais e militares ocupados $\mathrm{e}$ as honras recebidas); a leitura das inscrições e respectivo comentário.

L. Marcius Optatus foi primus profectus Asturio, um cargo cujas exactas características funcionais se desconhecem: por isso, Ojeda Torres lhe reservou o I apêndice; contém o II apêndice quadros que elucidam graficamente acerca da progressão, cargo por cargo, do cursus de cada cavaleiro.

Para facilitar a consulta, além do índice geral, preparou o Autor um índice onomástico e um rol dos cargos documentados, ordenado por províncias e cronologicamente.

Por fim, antecedida da lista de abreviaturas, a bibliografia consultada.

São do maior interesse os estudos prosopográficos, na medida em que eles permitem, como se disse, um esclarecimento cada vez maior das malhas de que o poder central se serviu para, ao longo dos séculos, manter coeso e funcional todo um sistema administrativo em tão amplo território. António Caballos Rufino fez, recentemente, idêntica investigação a propósito dos senadores hispano-romanos: Los Senadores Hispanorromanos y la Romanización de Hispania (siglos /-///): /. Prosopo grafía, 2 vol., Ecija, 1990. Leonard A. Curchin debruçou-se, por seu turno, sobre o escol das cidades peninsulares: The Local Magistrates of Roman Spain, Toronto, 1990. A nível mais geral, Segoulène Demougin escreveu, em 1992, Prosopo graphie des Chevaliers Romains Julio-Claudiens $(43$ av. J.-C. 70 ap. $\boldsymbol{J}-\boldsymbol{C}$.). Importa saber o mais exactamente possível quem foram os homenschave, para, depois, melhor se gizar o quadro da governação e do poder. E o papel da classe equestre tem-se revelado cada vez de maior interesse histórico, de forma que se tornou perfeitamente compreensível a realização, em Outubro de 1995, na Bélgica, de um colóquio internacional subordinado ao tema «A ordem equestre: história duma aristocracia (século II a. C. - século III d. C.).»

Não podemos, pois, deixar de aplaudir a iniciativa e aguardar que ela tenha o necessário seguimento. Permita-se-me, por isso, que faça ainda alguns comentários, com vista, inclusive, a um salutar debate de ideias.

São pouquíssimas as gralhas tipográficas, o que é notável num livro deste teor. Deixando de parte alguns parêntesis que faltam aqui e ali, anotemos a título de exemplo:

- na p. 132,1. 5, deverá ler-se M( arci) fi ilio);

- na p. 161, A. Coelho y F. Da Silva é uma só pessoa : Armando Coelho Ferreira da Silva; e deve ser citado pelo último apelido (SILVA);

- na p. 166,1. 5, Remos é com maiúscula;

- na p. 182, interrogo-me se CIL III 6753 não deverá considerar-se dedicado B(onae) F(ortunae) e também gostaria de ver explicitado o conteúdo do cargo propositus $X \boldsymbol{X}$ libertatis, que não vem indicado no currículo do cavaleiro, sintetizado na página seguinte.

Uma questão de ordem formal: citam-se, no comentário à biografia de cada eques, os textos em que se apoiam as afirmações, mas, de um modo geral, essa referência é feita de tal forma que o leitor menos atento poderá não se aperceber que se trata de fontes já referidas para a personagem em apreço. Exemplifico: a nota 5 da p. 172 refere CIL XIV 4500, que integra a documentação aduzida na p. 169; o mesmo se diga em relação à nota 10 da p. 173. 
Outra questão, meramente formal, prende-se com a bibliografia. Certamente o Autor teria poupado tempo e espaço se houvesse optado por incluir por extenso, no final ou no princípio, toda a bibliografia citada ao longo do volume quer no rol das obras referentes a cada personagem quer a que relegou para notas de rodapé. Assim, além de esse estratagema lhe possibilitar uma forma de citar mais sintética, evitaria que nos questionássemos sobre o critério que presidiu à exclusão, na bibliografia final, de autores a que alude, por exemplo, em notas. Creio, além disso, que a sua pesquisa terá sido exaustiva, embora, também aqui, haja sempre a possibilidade de acrescentar mais um nome: v. g., no caso de $\boldsymbol{P}$. Cominius Clemens, uma das epígrafes que se lhe refere foi igualmente estudada por Fulvio Mario BROILO (Iscrizioni Lapidarie del Museo Nazionale Concordiese di Portogruaro (Ia. C. - III d. C.), I, Roma, 1980, pp. 37-39.

$\mathrm{Na}$ p. 14, afirma Ojeda Torres, com base numa obra de Segoulène Demougin, que alguns cavaleiros iniciavam a sua carreira como centuriões, o que, dito desta maneira, pode, quiçá, induzir em erro. Creio que se trata da velha questão do primipilus, o primeiro centurião da primeira coorte duma legião, que tem sido considerado o limiar da carreira equestre para quem provém da actividade militar, problema que foi superiormente abordado por B. Dobson, em vários trabalhos, um deles citado pelo Autor, outro, que foi publicado em Aufstieg und Niedergang der Römischen Welt (Berlim, II, 1, 1974, pp. 392-434), intitulado "The significance of the centurion and "primipilaris" in the Roman army and administration».

É preciso - não nos cansamos de repetir - que alguém, um dia, faça um rol, de qualquer tipo que seja, para que se possa verificar se ele está, ou não, completo. Neste, se não erro, faltará apenas a menção a C. Iulius Celsus, atestado num texto patente no Museu de S. Miguel de Odrinhas (Sintra); uma omissão que, de certo modo, se justifica porque a sua «história» (apesar de referida na p. 24 da minha Introdução ao Estudo da Epigrafia Latina, Coimbra, 1987) foi contada por Scarlat Lambrino numa revista quase desconhecida em Espanha: Bulletin des Etudes Portugaises et de l'Institut Français au Portugal, Lisboa, nova série, 16, 1952 (um artigo publicado autonomamente, pela Coimbra Editora, em 1953, sob o título Les Inscriptions de São Miguel d'Odrinhas, em que a análise da epígrafe ocupa as pp. 13-21). Além de procurator provinciae Lusitaniae, após the terem sido atribuídas funções de menor categoria, C. Iulius Celsus exerceu um cargo palatino (a prefeitura «a libellis et a censibus») tendo ascendido, por adlectio, à categoria senatorial.

Vamos aguardar, pois, com o maior interesse o II volume, de integração histórica desta prosopografia. A onomástica - pela grande repercussão que têm os nomes das personagens ilustres - merecer-lhe-á, decerto, acurada reflexão. Nomes como Besius e Betuinianus (.$^{\circ}$ 5), Sentinatianus (.$^{\circ}$ 29), Truttedius (.$^{\circ}$ 54), Tuesianus (n. ${ }^{\circ}$ 19) são, pela sua raridade, passíveis de fornecer relevantes informações; o caso das adopções também. Por outro lado, os textos votivos mostrar-nos-ão como a religião estará impregnada, também aqui, de profunda intencionalidade política.

JOSÉ D’ENCARNAÇÃO 